\title{
Article \\ Perceived Produce Availability and Child Fruit and Vegetable Intake: The Healthy Communities Study
}

\author{
Laurel F. Moffat ${ }^{1}$, Lorrene D. Ritchie ${ }^{2}\left(\mathbb{D}\right.$, Wendi Gosliner ${ }^{2}\left(\mathbb{D}\right.$, Kaela R. Plank $^{2}$ and Lauren E. Au ${ }^{3, *(1)}$ \\ 1 Youth and Families Unit, Extension, Washington State University, Spokane, WA 99202, USA; \\ laurel.moffat@wsu.edu \\ 2 Nutrition Policy Institute, Division of Agriculture and Natural Resources, University of California, Oakland, \\ CA 94607, USA; lritchie@ucanr.edu (L.D.R.); wgosliner@ucanr.edu (W.G.); krplank@ucanr.edu (K.R.P.) \\ 3 Department of Nutrition, University of California, Davis, CA 95616, USA \\ * Correspondence: leau@ucdavis.edu; Tel.: +1-(530)-752-4630
}

Citation: Moffat, L.F.; Ritchie, L.D.; Gosliner, W.; Plank, K.R.; Au, L.E. Perceived Produce Availability and Child Fruit and Vegetable Intake: The Healthy Communities Study. Nutrients 2021, 13, 3681. https:// doi.org/10.3390/nu13113681

Academic Editors: Helmut Schroder and Santiago F. Gomez

Received: 29 September 2021 Accepted: 18 October 2021 Published: 20 October 2021

Publisher's Note: MDPI stays neutral with regard to jurisdictional claims in published maps and institutional affiliations.

Copyright: (c) 2021 by the authors. Licensee MDPI, Basel, Switzerland. This article is an open access article distributed under the terms and conditions of the Creative Commons Attribution (CC BY) license (https:/ / creativecommons.org/licenses/by/ $4.0 /)$.

\begin{abstract}
Children eat more fruits and vegetables when more are available at home, but less is known about how the neighborhood food environment relates to children's diet and weight outcomes. The goal of this study was to determine whether parental perception of the food environment (neighborhood and home) is associated with children's fruit and vegetable (F\&V) intake and weight outcomes, and to assess differences by household food security status and household income. Crosssectional data from the 2013-2015 U.S. Healthy Communities Study included 5138 children, aged 4 to 15 years old, from 130 U.S. communities. Neighborhood and home food environments were assessed with parent-reported, perceived F\&V availability scores. Associations were tested with multi-level linear regression models. Parents' perception of produce availability was associated with household $\mathrm{F} \& \mathrm{~V}$ availability ratings $(\beta=0.09$ points, $p<0.001)$. Household $\mathrm{F} \& \mathrm{~V}$ availability was associated with child F\&V intake ( $\beta=0.32$ cups / day or $25.6 \mathrm{~g} /$ day, $p<0.001)$. A higher child F\&V intake was associated with a lower child BMI z-score $(\beta=-0.05, p=0.002)$. Weaker relationships were seen for children living in food insecure or low-income households. Optimizing neighborhood and home access to F\&V may help children improve diet quality, but may not be as effective for children living in food insecure or low-income households.
\end{abstract}

Keywords: food environment; diet; fruits and vegetables; children

\section{Introduction}

Very few children in the United States (U.S.) meet the recommended daily intake for produce: less than $50 \%$ of children consume enough fruits, and less than $12 \%$ consume enough vegetables [1]. A low intake of fruits and vegetables has been linked to obesity, hypertension, coronary heart disease, stroke, and cancer [2]. Many factors contribute to low fruit and vegetable intake and associated chronic diseases, which is why the American Academy of Pediatrics (AAP) and the Centers for Disease Control and Prevention recommend a multi-level approach to establishing healthy dietary patterns and preventing obesity, addressing the neighborhood and home food environments in addition to individual-level dietary factors [3,4]. However, the nature of the relationships between food environments, children's fruit and vegetable intake, and weight status requires further investigation to identify the most promising strategies to optimize child health.

Strong evidence suggests that food availability in the home is associated with children's fruit and vegetable intake, which is supported by three systematic reviews that found positive associations between the availability of fruits and vegetables inside the home and child produce intake [5-7]. Evidence is weaker for the association between children's fruit and vegetable intake and body mass index (BMI), but the AAP recommends including increased produce consumption in obesity prevention strategies for its low calorie, high nutrient density, and other health benefits [4]. The role of the neighborhood food 
environment in children's fruit and vegetable intake is also unclear. In the one review that assessed neighborhood environment and diet, researchers found a moderately strong relationship, but called for additional studies and better validation of environmental measures [8]. Studies of food environment interventions, such as corner store conversions and the introduction of grocery stores, have found minor improvements in fruit and vegetable intake [9]. While previous studies of children's diets and BMI have focused on either neighborhood or home food environments, few studies have examined the relationships between all four levels: the neighborhood food environment, home food environment, child eating behavior, and child body weight.

Many factors may influence the relationship between neighborhood and home food environments and the dietary intakes of children, but few studies have tried to quantify interactions with household income and food security, which is characterized by a lack of reliable access to adequate food [10]. Previous studies have shown an association between household food security and income with reduced in-home produce availability and fruit consumption, but studies have reported conflicting findings related to whether food security status moderates the relationship between food environments and diet [11-13]. A 2019 review of the associations between food environments and diet by household income found some evidence that a low household income is associated with stronger relationships between food environments and diet, when measuring neighborhood environments using food pricing; one study that examined these relationships using perceived food environments found that adolescents from lower-income families were more responsive to a negative food environment (greater access to fast food and convenience stores was associated with an unhealthier diet) [14].

The primary aim of this study was to determine whether there were associations between parents' perceptions of produce availability in their neighborhood, household fruit and vegetable availability, child fruit and vegetable intake, and child BMI z-score. The hypothesis was that higher perceptions of neighborhood produce availability by parents would be associated with higher household produce availability, higher child consumption of fruits and vegetables, and lower child BMI. A secondary aim was to determine whether any significant relationships in these variables varied by household food security status or annual household income. The hypothesis was that children living in food insecure and low-income households would have lower household fruit and vegetable availability and consumption, and higher BMI z-scores than children living in food secure and higher income households, regardless of parent perceptions of neighborhood produce availability.

\section{Materials and Methods}

\subsection{Study Design}

The 2013-2015 Healthy Communities Study measured associations among community programs and policies and obesity-related outcomes in a sample of 5138 children aged 4-15 years old in the United States [15]. The study was observational and used clustered sampling by community and by school. Communities, defined as high school catchment areas, were selected either because they had known child obesity interventions $(n=28)$ or through national probability-based sampling $(n=102)$. For the latter, communities were stratified by region of the U.S., urbanicity, race/ethnicity, and income, then sampled with probabilities proportional to the number of children aged 4-15 years living in the community [16]. Up to two public elementary and two public middle schools were selected from each community, and children were recruited from each school [17].

Children and adult caregivers (hereafter referred to as parents) were interviewed in their homes by trained data collectors [17]. For questions asked of children, parents were the primary respondent if children were under 8 years old; otherwise, parents were present to assist if needed [18]. Parents were the primary respondents for questions about the household. All procedures involving research study participants were approved by the Battelle Memorial Institute IRB. Written informed consent was obtained from all parents, and children aged 8 years or older provided written assent. 


\subsection{Measures}

For the perceived neighborhood availability of produce (i.e., fresh fruits and vegetables), parents were asked to rate how much they agreed with statements that there is a large selection of produce, it is high quality, and it is easy to purchase (1-disagree a lot, 2disagree a little, 3-agree a little, or 4-agree a lot). Responses to these three questions were averaged and combined into one composite score for perceived neighborhood produce availability. For household fruit and vegetable availability, parents were asked how often fruits and dark green vegetables were typically available in their home (0-never, 1 -rarely, 2-sometimes, 3-often, or 4-very often), and the responses to these two questions were averaged.

Child fruit and vegetable intake was measured with a Dietary Screener Questionnaire developed by the National Cancer Institute [19]. Daily fruit and vegetable intake in cups / day ( 1 cup = $80 \mathrm{~g}$ ) was calculated based on fruit, vegetable, and legume consumption frequency over the past month, including 100\% fruit juice and excluding fried potatoes [18]. Fried potatoes, but not baked, boiled, or other potatoes, were excluded from the fruit and vegetable calculation because they are considered energy-dense foods of minimal nutritional value [18]. Using a protocol developed by the National Cancer Institute, nationally representative sex- and age-specific mean daily intakes from $24-\mathrm{h}$ recalls were used to convert frequencies into cups per day consumed. Child height and weight were measured using standard protocols, and age- and sex-adjusted BMI z-scores were calculated using the 2000 CDC Growth Charts [20]. Household food insecurity status was determined using a validated subset of two items from the U.S. Department of Agriculture's Food Security Survey Modules [21]. Parents reported household food insecurity (often true, sometimes true, or never true) based on two questions: (1) "Within the past 12 months we worried whether our food would run out before we got money to buy more" and (2) "Within the past 12 months the food we bought just did not last and we did not have money to get more". Households were classified as food insecure if responses were affirmative (often or sometimes) to one or both items. Annual household income was based on the self-reported income level. Other demographic factors were measured via parent survey questions, and community information was collected for census tracts from the 2009-2013 American Community Survey [16].

\subsection{Data Analysis}

Missing data were addressed using multiple imputation. Multilevel linear regression models adjusted for random effects (community and school) and covariates were used to test associations between variables of interest:

- Model 1: perceived neighborhood produce availability score (predictor) in relation to household fruit and vegetable availability score (outcome).

- Model 2: perceived neighborhood produce availability score (predictor) in relation to child fruit and vegetable intake (outcome).

- Model 3: household fruit and vegetable availability score (predictor) in relation to child fruit and vegetable intake (outcome).

- Model 4: perceived neighborhood produce availability score (predictor) in relation to child BMI z-score (outcome).

- Model 5: household fruit and vegetable availability score (predictor) in relation to child BMI z-score (outcome).

- Model 6: child fruit and vegetable intake (predictor) in relation to child BMI z-score (outcome).

Covariates for models with child fruit and vegetable intake and BMI z-score as outcomes were selected using the least absolute shrinkage and selection operator (LASSO) method [22]. Covariates for models with child fruit and vegetable intake as the outcome included the following: annual household income, maximum parent education, maximum parent employment, child race, child ethnicity, season of the year, region of the U.S., community percent minority, community urbanicity, community percent African American, 
community percent Hispanic, community percent in poverty, and community percent unemployed. The model with the household fruit and vegetable availability score as the outcome used the same covariates. Covariates for models with child BMI z-score as the outcome included the following: annual household income, child height, paternal education, maternal employment, child ethnicity, region of the U.S., and community percent minority. Significant associations were then tested for interaction by household food insecurity status and by annual household income. Analyses were performed using SAS 9.4 (SAS Institute, Cary, NC, USA) with significance determined by $p<0.05$.

\section{Results}

The average age of children in this sample was 9 years old (Table 1). Approximately half of the children were female, and just under half (45\%) were Hispanic. Forty-one percent of children were classified as overweight or obese based on having a BMI above the age- and sex-specific 85th percentile. Forty-three percent of parents had a maximum education level of high school or less, and in most households (73\%) at least one parent was working full time. Forty-five percent of the households surveyed had experienced food insecurity in the past year, and half of the households had total annual incomes of $\$ 35,000$ or less. The children lived in communities that varied in terms of location, but were most often located in the South $(42 \%)$ and were classified as suburban $(40 \%)$ or urban $(38 \%)$. Communities on average were one-third Hispanic or Latino and one-fifth African American, and had a poverty rate of $21 \%$. On average (mean $\pm \mathrm{SD}$ ), parents rated the produce availability in their communities as $3.4( \pm 0.8)$ out of 4 points (with a score of 4 signifying high agreement with large selection, high quality, and ease of purchasing statements). The mean household fruit and vegetable availability score was $3.3 \pm 0.7$ out of 4 points (with a score of 4 signifying frequent availability of both fruits and dark green vegetables). On average, children consumed $2.5 \pm 0.9$ cups of fruits and vegetables per day and had a BMI z-score of $0.7 \pm 1.2$. Perceived neighborhood produce availability scores varied by region of the U.S., community urbanicity, household annual income, and household food insecurity status, with the highest average scores in the Western region ( $3.5 \pm 0.7$ points, $p<0.001$, data not shown), suburban communities $(3.5 \pm 0.7, p<0.001$, data not shown), households earning more than $\$ 35,000$ (3.5 $\pm 0.7, p<0.001$, data not shown), and food secure households ( $3.5 \pm 0.7, p<0.001$, data not shown).

Parents' perception of produce availability in their neighborhood was positively associated with household fruit and vegetable availability ratings (Table 2). Each onepoint increase in perceived neighborhood produce availability score was associated with a 0.09 -point higher average household fruit and vegetable availability score $(95 \% \mathrm{CI}$ : $0.06,0.11)$. The perceived neighborhood produce availability score was not associated with the children's average fruit and vegetable intake or children's average BMI z-score. Parents' rating of household fruit and vegetable availability was positively associated with children's fruit and vegetable intake. Each one-point increase in household fruit and vegetable availability score was associated with a 0.32 cup increase children's average daily fruit and vegetable consumption ( $95 \%$ CI: $0.28,0.35$ ). The household-level availability score was not associated with the children's average BMI z-score. Fruit and vegetable intake by children was negatively associated with the child BMI z-score. Each additional cup of fruits and vegetables consumed by children was associated with a 0.05 lower child BMI z-score on average ( $95 \% \mathrm{CI}:-0.09,-0.02)$. 
Table 1. Characteristics of children, households, and communities in the Healthy Communities Study ( $\mathrm{N}=5138$ children, 130 communities).

\begin{tabular}{|c|c|c|}
\hline Child and Household Characteristics & $n$ & $\%$ \\
\hline Female child & 2614 & 50.9 \\
\hline \multicolumn{3}{|l|}{ Child race/ethnicity } \\
\hline Hispanic or Latino & 2295 & 44.7 \\
\hline Non-Hispanic White & 1520 & 29.6 \\
\hline Non-Hispanic African American & 927 & 18.0 \\
\hline Non-Hispanic Other & 396 & 7.7 \\
\hline Child overweight or obese & 2081 & 40.5 \\
\hline Household food insecure & 2293 & 44.6 \\
\hline \multicolumn{3}{|l|}{ Household annual income } \\
\hline Up to $\$ 35,000$ & 2640 & 51.4 \\
\hline Greater than $\$ 35,000$ & 2498 & 48.6 \\
\hline \multicolumn{3}{|l|}{ Maximum parent education level for biological parents } \\
\hline Less than high school & 1166 & 22.7 \\
\hline High school diploma, GED or equivalent & 1038 & 20.2 \\
\hline Some college or Associate Degree & 1284 & 25.0 \\
\hline Bachelor's Degree & 786 & 15.3 \\
\hline Graduate Degree & 868 & 16.9 \\
\hline \multicolumn{3}{|l|}{ Maximum employment status of biological parents } \\
\hline Working full-time for pay & 3747 & 72.9 \\
\hline Working part-time for pay & 518 & 10.1 \\
\hline Unemployed & 313 & 6.1 \\
\hline Other & 539 & 10.5 \\
\hline \multicolumn{3}{|l|}{ Community Characteristics } \\
\hline \multicolumn{3}{|l|}{ U.S. region } \\
\hline Midwest & 991 & 19.3 \\
\hline Northeast & 791 & 15.4 \\
\hline South & 2135 & 41.6 \\
\hline West & 1221 & 23.8 \\
\hline \multicolumn{3}{|l|}{ Urbanicity } \\
\hline Rural & 1162 & 22.6 \\
\hline Suburban & 2034 & 39.6 \\
\hline \multirow{3}{*}{ Child and Household Characteristics } & 1942 & 37.8 \\
\hline & Mean & SD \\
\hline & 9.3 & 2.7 \\
\hline Community Characteristics & & \\
\hline
\end{tabular}

Community race/ethnicity

Percent of population aged 5 to 14 years that are African American $\quad \begin{array}{lll}19.7 & 23.4\end{array}$

$\begin{array}{lll}\text { Percent of population aged } 5 \text { to } 14 \text { years that are Hispanic } & 34.7 & 29.6\end{array}$

Community socioeconomic status

$\begin{array}{lll}\text { Percent of population below the federal poverty level } & 20.6 & 10.6\end{array}$

Percent of population in labor force 16 years and over who are unemployed $\quad \begin{array}{lll}8.8 & 3.4\end{array}$

Outcomes

\begin{tabular}{lll}
\hline Perceived neighborhood produce availability score $^{1}$ & 3.4 & 0.8 \\
$\quad$ Ease of access $^{1}$ & 3.5 & 0.8 \\
Variety $^{1}$ & 3.4 & 0.9 \\
Quality $^{1}$ & 3.2 & 0.9 \\
Household fruit and vegetable availability score $^{2}$ & 3.3 & 0.7 \\
$\quad$ Fruit availability $^{2}$ & 3.1 & 0.9 \\
$\quad$ Dark green vegetable availability $^{2}$ & 3.5 & 0.7 \\
Child fruit and vegetable intake (cups $/$ day) $^{3}$ & 2.5 & 0.9 \\
Body-mass-index-for-age-z-score (BMI z-score) $^{3}$ & 0.7 & 1.2
\end{tabular}

${ }^{1}$ Questions on neighborhood produce (ease of purchasing, large selection, and high quality) were scored as follows: 1 -disagree a lot, 2-disagree a little, 3-agree a little, or 4-agree a lot. ${ }^{2}$ Questions on the frequency of the availability of fruits and dark green vegetables at home were scored as follows: 0-never, 1-rarely, 2 - sometimes, 3 - often, or 4 - very often. ${ }^{3}$ One cup is approximately equivalent to $80 \mathrm{~g}$ of fruits and vegetables. 
Table 2. Associations between perceived neighborhood produce availability and household fruit and vegetable availability, child fruit and vegetable intake, and child body mass index z-score (BMI z-score) in the Healthy Communities Study $(\mathrm{N}=5138)$.

\begin{tabular}{|c|c|c|c|c|c|}
\hline Model & Predictor & Outcome & $\beta$ & $95 \%$ CI & $p$ \\
\hline 1 & $\begin{array}{c}\text { Perceived neighborhood } \\
\text { produce availability score }\end{array}$ & $\begin{array}{c}\text { Household fruit and vegetable } \\
\text { availability score } \\
\end{array}$ & 0.09 & $0.06,0.11$ & $<0.001$ \\
\hline 2 & $\begin{array}{c}\text { Perceived neighborhood } \\
\text { produce availability score }\end{array}$ & $\begin{array}{l}\text { Child fruit and vegetable intake } \\
\text { (cups/day) }{ }^{3}\end{array}$ & 0.03 & $0.00,0.07$ & 0.08 \\
\hline 3 & $\begin{array}{c}\text { Household fruit and } \\
\text { vegetable availability score }\end{array}$ & $\begin{array}{l}\text { Child fruit and vegetable intake } \\
\text { (cups/day) }{ }^{3}\end{array}$ & 0.32 & $0.28,0.35$ & $<0.001$ \\
\hline 4 & $\begin{array}{c}\text { Perceived neighborhood } \\
\text { produce availability score }\end{array}$ & Child BMI z-score ${ }^{4}$ & -0.03 & $-0.07,0.02$ & 0.25 \\
\hline 5 & $\begin{array}{c}\text { Household fruit and } \\
\text { vegetable availability score } 2\end{array}$ & Child BMI z-score ${ }^{4}$ & 0.00 & $-0.05,0.04$ & 0.83 \\
\hline 6 & $\begin{array}{l}\text { Child Fruit and vegetable } \\
\text { intake (cups/day) }\end{array}$ & Child BMI z-score ${ }^{4}$ & -0.05 & $-0.09,-0.02$ & 0.002 \\
\hline
\end{tabular}

\footnotetext{
${ }^{1}$ Questions on neighborhood produce (ease of purchasing, large selection, and high quality) were scored as follows: 1-disagree a lot, 2-disagree a little, 3-agree a little, or 4-agree a lot. ${ }^{2}$ Questions on frequency of availability of fruits and dark green vegetables at home were scored as follows: 0 -never, 1 -rarely, 2-sometimes, 3-often, or 4-very often. ${ }^{3}$ Models 1-3 are adjusted for the following covariates: annual household income, maximum parent education, maximum parent employment, child race, child ethnicity, season of the year, region of the U.S., percent minority in census tract, community urbanicity, community percent African American, community percent Hispanic, community percent in poverty, and community percent unemployed. ${ }^{4}$ Models $4-6$ are adjusted for the following covariates: annual household income, child height, paternal education, maternal employment, child ethnicity, region of the U.S., and percent minority in census tract.
}

The association between the perceived neighborhood produce availability score and household fruit and vegetable availability did not vary by household food security status $(p$-interaction $=0.05)($ Table 3$)$. The association between household fruit and vegetable availability score and child fruit and vegetable intake varied by food insecurity status (p-interaction $=0.03$ ). Among food insecure households, a one-point increase in household fruit and vegetable availability score was associated with a smaller increase in average child fruit and vegetable intake ( 0.28 cups/day, $95 \%$ CI: $0.23,0.33)$ compared with food secure households ( 0.36 cups / day; $95 \%$ CI: $0.30,0.42)$. The association between child fruit and vegetable intake and child BMI z-score also varied by food security status ( $p$-interaction $=0.01$ ). Among children in food insecure households, increased fruit and vegetable intake was not associated with a change in the average BMI z-score (95\% CI: $-0.05,0.05)$. Among children in food secure households, each additional cup of fruits and vegetables consumed per day was associated with a 0.10 lower average BMI z-score (95\% CI: $-0.14,-0.05)$.

The association between perceived neighborhood produce availability and household fruit and vegetable availability scores did not vary by household income ( $\mathrm{p}$-interaction $=0.80$ ) (Table 4). Low-income households compared to high-income households had a smaller average increase in child fruit and vegetable intake for every one-point increase in household fruit and vegetable availability ( 0.28 cups/day vs. 0.37 cups/day, respectively; $\mathrm{p}$-interaction $=0.02)$. The association between child fruit and vegetable intake and average child BMI z-score did not vary by household income ( $\mathrm{p}$-interaction $=0.33$ ). 
Table 3. Select relationships between perceived neighborhood produce availability, household fruit and vegetable availability, child fruit and vegetable intake, and child body mass index z-score (BMI z-score) in the Healthy Communities Study, by household food security status $(\mathrm{N}=5138)$.

\begin{tabular}{|c|c|c|c|c|c|c|}
\hline \multirow[b]{2}{*}{ Predictor } & \multirow[b]{2}{*}{ Outcome } & \multicolumn{2}{|c|}{$\begin{array}{c}\text { Food Insecure } \\
\text { Households }{ }^{1}(n=2293)\end{array}$} & \multicolumn{2}{|c|}{$\begin{array}{c}\text { Food Secure } \\
\text { Households } \\
\text { He }(n=2845)\end{array}$} & \multirow[b]{2}{*}{$p$ Interaction } \\
\hline & & $\beta$ & $95 \%$ CI & $\beta$ & $95 \%$ CI & \\
\hline $\begin{array}{l}\text { Perceived neighborhood produce } \\
\text { availability score }\end{array}$ & $\begin{array}{l}\text { Household fruit and vegetable } \\
\text { availability score } \\
3,4\end{array}$ & 0.10 & $0.07,0.14$ & 0.06 & $0.02,0.09$ & 0.05 \\
\hline $\begin{array}{l}\text { Household fruit and vegetable } \\
\text { availability score }\end{array}$ & $\begin{array}{l}\text { Child fruit and vegetable intake } \\
\text { (cups/day) }{ }^{4}\end{array}$ & 0.28 & $0.23,0.33$ & 0.36 & $0.30,0.42$ & 0.03 \\
\hline $\begin{array}{l}\text { Child Fruit and vegetable intake } \\
\text { (cups/day) }\end{array}$ & Child BMI z-score ${ }^{5}$ & 0.00 & $-0.05,0.05$ & -0.10 & $-0.14,-0.05$ & 0.01 \\
\hline
\end{tabular}

${ }^{1}$ Food insecurity status was determined using a validated two-item screener. ${ }^{2}$ Questions on neighborhood produce (ease of purchasing, large selection, and high quality) were scored as follows: 1 -disagree a lot, 2-disagree a little, 3-agree a little, or 4-agree a lot. ${ }^{3}$ Questions on frequency of the availability of fruits and dark green vegetables at home were scored as follows: 0 -never, 1 -rarely, 2-sometimes, 3-often, or 4-very often. ${ }^{4}$ Models are adjusted for the following covariates: household food security status, perceived neighborhood produce availability score, annual household income, maximum parent education, maximum parent employment, child race, child ethnicity, season of the year, region of the U.S., community urbanicity, percent minority in census tract, community percent African American, community percent Hispanic, community percent in poverty, and community percent unemployed. ${ }^{5}$ Model is adjusted for the following covariates: household food security status, child fruit and vegetable intake, annual household income, child height, paternal education, maternal employment, child ethnicity, region of the U.S., and percent minority in census tract.

Table 4. Select relationships between perceived neighborhood produce availability, household fruit and vegetable availability, child fruit and vegetable intake, and child body mass index z-score (BMI z-score) in the Healthy Communities Study, by annual household income $(\mathrm{N}=5138)$.

\begin{tabular}{|c|c|c|c|c|c|c|}
\hline \multirow[b]{2}{*}{ Predictor } & \multirow[b]{2}{*}{ Outcome } & \multicolumn{2}{|c|}{$\begin{array}{c}\text { Low-Income } \\
\text { Households }^{1}(n=2640)\end{array}$} & \multicolumn{2}{|c|}{$\begin{array}{c}\text { High-Income } \\
\text { Households }^{1}(n=2498)\end{array}$} & \multirow[b]{2}{*}{$p$ Interaction } \\
\hline & & $\beta$ & $95 \% \mathrm{CI}$ & $\beta$ & $95 \% \mathrm{CI}$ & \\
\hline $\begin{array}{l}\text { Perceived neighborhood produce } \\
\text { availability score } \\
\text { avali }\end{array}$ & $\begin{array}{l}\text { Household fruit and vegetable } \\
\text { availability score }\end{array}$ & 0.09 & $0.06,0.12$ & 0.09 & $0.05,0.12$ & 0.80 \\
\hline $\begin{array}{l}\text { Household fruit and vegetable } \\
\text { availability score }\end{array}$ & $\begin{array}{l}\text { Child fruit and vegetable intake } \\
\text { (cups/day) } 4\end{array}$ & 0.28 & $0.23,0.33$ & 0.37 & $0.31,0.43$ & 0.02 \\
\hline $\begin{array}{l}\text { Child fruit and vegetable intake } \\
\text { (cups/day) }\end{array}$ & Child BMI z-score ${ }^{5}$ & -0.04 & $-0.09,0.01$ & -0.07 & $-0.13,-0.02$ & 0.33 \\
\hline \multicolumn{7}{|c|}{$\begin{array}{l}{ }^{1} \text { Households were considered low-income if parents reported annual household earnings less than } \$ 35,000 .{ }^{2} \text { Questions on neighborhood } \\
\text { produce (ease of purchasing, large selection, and high quality) were scored as follows: } 1-\text { disagree a lot, } 2-\text { disagree a little, } 3-\text { agree } \\
\text { a little, or } 4 \text {-agree a lot. }{ }^{3} \text { Questions on the frequency of the availability of fruits and dark green vegetables at home were scored as } \\
\text { follows: } 0 \text {-never, 1-rarely, } 2 \text { - sometimes, } 3 \text { - often, or } 4-\text { very often. }{ }^{4} \text { Models are adjusted for the following covariates: perceived } \\
\text { neighborhood produce availability score, maximum parent education, maximum parent employment, child race, child ethnicity, season of } \\
\text { the year, region of the U.S., community urbanicity, percent minority in census tract, community percent African American, community } \\
\text { percent Hispanic, community percent in poverty, and community percent unemployed. }{ }^{5} \text { Model is adjusted for the following covariates: } \\
\text { child fruit and vegetable intake, child height, paternal education, maternal employment, child ethnicity, region of the U.S., and percent } \\
\text { minority in census tract. }\end{array}$} \\
\hline
\end{tabular}

\section{Discussion}

Improved perception of produce availability at the neighborhood-level was associated with a higher produce availability at the household-level, which in turn was related to improved fruit and vegetable intake at the individual-level. Higher fruit and vegetable intake among children was associated with a lower BMI, which has been found in previous studies with adults [23-26], but has been shown with mixed results in children [27]. These results are consistent with reviews that found positive associations between home food availability and child produce intake [5-7], and further support the connection between the perceived neighborhood food environment and the home food environment. The associations between produce availability, intake, and BMI suggest a pathway between neighborhood-level, household-level, and individual-level factors that is consistent with the study hypothesis that the four factors are related. These connections between community, 
household, and individual factors are also consistent with the IOM's multilevel model of eating behavior and body weight determinants [28].

The findings from this study align with those observed in the 2008-2010 INPACT study of 1501 Dutch families, which found that parents' perceptions of the neighborhood food environment were associated with produce availability at home, but neighborhood measures were not associated with children's fruit and vegetable intake [29]. The results are also consistent with the M-TEENs study of 903 U.S. adolescents, which found associations between home food availability and children's diet, but no connections between the neighborhood food environment and children's diet and BMI [30]. It is likely that associations across multiple levels (neighborhood availability relating to children's intake or household availability relating to children's weight status) were not seen because additional factors at each level combine with the effects of food environments to predict eating behaviors and weight status. For example, parents' eating preferences, behaviors, and encouragement could be just as predictive of child intake as home produce availability [5-7,30-34]. Therefore, this study's results confirm that food environments play an important but not exclusive role in children's fruit and vegetable consumption.

Household food security status and annual income modified some associations. The associations between household produce availability and child fruit and vegetable intake and between child fruit and vegetable intake and child BMI z-score had smaller effect sizes among children living in food insecure households. These results are consistent with a 2016 study of barriers to fruit and vegetable consumption among 531 adults from Oakland, CA, in which food insecurity was associated with weaker or nonsignificant associations between barriers and consumption, suggesting that food insecurity may attenuate the effects of other factors on consumption [13]. Annual household income had a similar interaction on the association between household produce availability and child fruit and vegetable intake. Among children living in low-income households, greater availability was associated with smaller improvements in intake, which is in contrast to a previous review that showed stronger associations between food environment and diet among low-income participants when the food environment was measured using food prices [14].

The strengths of this study include that this was one of the first national studies to include both the neighborhood and home food environments in an analysis of children's fruit and vegetable intake, and it examined how food security and income modified these relationships. Furthermore, the Healthy Communities Study had a large sample size and high proportion of participants who reported household food insecurity or low annual income relative to similar studies, improving the power in these subgroups.

Limitations of the study include that availability and diet measures were self-reported, which increased the risk of reporting and recall bias by sociodemographic factors $[8,35]$. Neighborhood produce availability was measured based on adults' perceptions instead of objective assessment, although there is some evidence that the perceived availability better captures the true experience of food accessibility because respondents will consider safety, transportation access, and other experiential factors in their assessment of food access [8]. Household food availability was also assessed using parent self-report, and measures of vegetable availability were limited to only dark green vegetables. The neighborhood availability score included "ease of purchasing" instead of perceptions of food prices or "affordability", both of which are known to affect perceived food availability and purchasing behavior [36].

The findings from this study suggest that interventions may not find direct relationships between changes in local food environments and children's fruit and vegetable intake or BMI, and that the household-level food environment and household food insecurity and income may play important intermediary roles in the relationship between these factors. Further analyses should explore the role of household fruit and vegetable availability as a mediator between perceived neighborhood produce availability and child fruit and vegetable intake. Food environment interventions to increase the access, variety, and quality of fruits and vegetables in a neighborhood should consider the household-level 
food environment, household food security status, and household income when assessing impacts on children's fruit and vegetable intake.

Author Contributions: Conceptualization, L.D.R.; methodology, L.F.M., L.E.A., and K.R.P.; software, L.F.M.; formal analysis, L.F.M., K.R.P., and L.E.A.; writing-original draft preparation, L.F.M.; writing-review and editing, L.E.A., L.D.R., W.G., and K.R.P.; visualization, L.F.M.; supervision, L.E.A.; funding acquisition, L.E.A. All authors have read and agreed to the published version of the manuscript.

Funding: This research was funded by the National Heart, Lung, and Blood Institute of the National Institutes of Health, grant number K01HL131630. The content is solely the responsibility of the authors and does not necessarily represent the official views of the National Institutes of Health. The funding source had no role in the design and conduct of the study; collection, management, analysis, and interpretation of the data; preparation, review, or approval of the manuscript; and decision to submit the manuscript for publication.

Institutional Review Board Statement: This study was conducted according to the guidelines of the Declaration of Helsinki and was approved by the Institutional Review Board of the Battelle Memorial Institute (protocol code FG006608 approved on 24 February 2012).

Informed Consent Statement: Informed consent was obtained from all subjects involved in the study. Parents provided written informed consent for their children's participation, and children aged $\geq 8$ years or older provided written consent.

Data Availability Statement: Data are available in a publicly accessible repository that does not issue DOIs. Publicly available datasets were analyzed in this study. This data can be found here: https:/ /biolincc.nhlbi.nih.gov/studies/hcs/ (accessed on 18 October 2021).

Acknowledgments: The authors would like to acknowledge Marisa Tsai and Sridharshi Hewawitharana for their support with the data analysis.

Conflicts of Interest: The authors declare no conflict of interest. The funders had no role in the design of the study; in the collection, analyses, or interpretation of data; in the writing of the manuscript; or in the decision to publish the results.

\section{References}

1. CDC. Children Eating More Fruit, but Fruit and Vegetable Intake Still Too Low. CDC Online Newsroom. Available online: https:/ / www.cdc.gov/media/releases/2014/p0805-fruits-vegetables.html (accessed on 9 September 2020).

2. Boeing, H.; Bechthold, A.; Bub, A.; Ellinger, S.; Haller, D.; Kroke, A.; Leschik-Bonnet, E.; Müller, M.J.; Oberritter, H.; Schulze, M.; et al. Critical review: Vegetables and fruit in the prevention of chronic diseases. Eur. J. Nutr. 2012, 51, 637-663. [CrossRef]

3. Centers for Disease Control and Prevention. Morbidity and Mortality Weekly Report: Recommended Community Strategies and Measurements to Prevent Obesity in the United States; Centers for Disease Control and Prevention: Atlanta, GA, USA, 2009; Volume 58, pp. 1-26.

4. Davis, M.M.; Gance-Cleveland, B.; Hassink, S.; Johnson, R.; Paradis, G.; Resnicow, K. Recommendations for prevention of childhood obesity. Pediatrics 2007, 120 (Suppl. S4), S229-S253. [CrossRef]

5. Ong, J.X.; Ullah, S.; Magarey, A.; Miller, J.; Leslie, E. Relationship between the home environment and fruit and vegetable consumption in children aged 6-12 years: A systematic review. Public Health Nutr. 2016, 20, 464-480. [CrossRef] [PubMed]

6. Yee, A.Z.H.; Lwin, M.O.; Ho, S.S. The influence of parental practices on child promotive and preventive food consumption behaviors: A systematic review and meta-analysis. Int. J. Behav. Nutr. Phys. Act. 2017, 14, 47. [CrossRef] [PubMed]

7. Pearson, N.; Biddle, S.J.; Gorely, T. Family correlates of fruit and vegetable consumption in children and adolescents: A Systematic review. Public Health Nutr. 2009, 12, 267. [CrossRef] [PubMed]

8. Caspi, C.E.; Sorensen, G.; Subramanian, S.V.; Kawachi, I. The local food environment and diet: A systematic review. Health Place 2012, 18, 1172-1187. [CrossRef] [PubMed]

9. Hasanthi Abeykoon, A.; Engler-Stringer, R.; Muhajarine, N. Health-related outcomes of new grocery store interventions: A systematic review. Public Health Nutr. 2017, 20, 2236-2248. [CrossRef]

10. USDA ERS. Definitions of Food Security. Available online: https://www.ers.usda.gov/topics/food-nutrition-assistance/foodsecurity-in-the-us/definitions-of-food-security / (accessed on 2 March 2021).

11. Poulsen, M.N.; Bailey-Davis, L.; Pollak, J.; Hirsch, A.G.; Schwartz, B.S. Household food insecurity and home food availability in relation to youth diet, body mass index, and adiposity. J. Acad. Nutr. Diet. 2019, 119, 1666-1675. [CrossRef]

12. Hanson, K.L.; Connor, L.M. Food insecurity and dietary quality in US adults and children: A systematic review. Am. J. Clin. Nutr. 2014, 100, 684-692. [CrossRef] 
13. Mook, K.; Laraia, B.A.; Oddo, V.M.; Jones-Smith, J.C. Food security status and barriers to fruit and vegetable consumption in two economically deprived communities of Oakland, California, 2013-2014. Prev. Chronic Dis. 2016, 13, 150402. [CrossRef]

14. Mackenbach, J.D.; Nelissen, K.G.M.; Dijkstra, S.C.; Poelman, M.P.; Daams, J.G.; Leijssen, J.B.; Nicolaou, M. A Systematic review on socioeconomic differences in the association between the food environment and dietary behaviors. Nutrients 2019, $11,2215$. [CrossRef]

15. Sonia Arteaga, S.; Loria, C.M.; Crawford, P.B.; Fawcett, S.B.; Fishbein, H.A.; Gregoriou, M.; John, L.V.; Kelley, M.; Pate, R.R.; Ritchie, L.D.; et al. The healthy communities study: Its rationale, aims, and approach. Am. J. Prev. Med. 2015, 49, 615-623. [CrossRef] [PubMed]

16. Strauss, W.J.; Sroka, C.J.; Frongillo, E.A.; Sonia Arteaga, S.; Loria, C.M.; Leifer, E.S.; Wu, C.O.; Patrick, H.; Fishbein, H.A.; John, L.V. Statistical design features of the healthy communities study. Am. J. Prev. Med. 2015, 49, 624-630. [CrossRef] [PubMed]

17. John, L.V.; Gregoriou, M.; Pate, R.R.; Fawcett, S.B.; Crawford, P.B.; Strauss, W.J.; Frongillo, E.A.; Ritchie, L.D.; Loria, C.M.; Kelley, M.; et al. Operational implementation of the healthy communities study: How communities shape children's health. Am. J. Prev. Med. 2015, 49, 631-635. [CrossRef] [PubMed]

18. Ritchie, L.D.; Wakimoto, P.; Woodward-Lopez, G.; Thompson, F.E.; Loria, C.M.; Wilson, D.K.; Kao, J.; Crawford, P.B.; Webb, K.L. The healthy communities study nutrition assessments: Child diet and the school nutrition environment. Am. J. Prev. Med. 2015, 49,647-652. [CrossRef] [PubMed]

19. National Cancer Institute (NCI). Dietary Screener Questionnaire in the NHANES 2009-10: Background; National Cancer Institute: Bethesda, MD, USA, 2021.

20. Kuczmarski, R.J.; Ogden, C.L.; Guo, S.S.; Grummer-Strawn, L.M.; Flegal, K.M.; Mei, Z.; Wei, R.; Curtin, L.R.; Roche, A.F.; Johnson, C.L. 2000 CDC growth charts for the United States: Methods and development. Vital Health Stat. 2002, 11, 1-203.

21. Hager, E.R.; Quigg, A.M.; Black, M.M.; Coleman, S.M.; Heeren, T.; Rose-Jacobs, R.; Cook, J.T.; Ettinger De Cuba, S.A.; Casey, P.H.; Chilton, M.; et al. Development and validity of a 2-item screen to identify families at risk for food insecurity. Pediatrics 2010, 126, e26-e32. [CrossRef]

22. Tibshirani, R. Regression shrinkage and selection via the lasso. Source J. R. Stat. Soc. Ser. B 1996, 58, 267-288. [CrossRef]

23. Nour, M.; Lutze, S.A.; Grech, A.; Allman-Farinelli, M. The relationship between vegetable intake and weight outcomes: A systematic review of cohort studies. Nutrients 2018, 10, 1626. [CrossRef]

24. Rautiainen, S.; Wang, L.; Lee, I.M.; Manson, J.E.; Buring, J.E.; Sesso, H.D. Higher Intake of fruit, but not vegetables or fiber, at baseline is associated with lower risk of becoming overweight or obese in middle-aged and older women of normal BMI at baseline. J. Nutr. 2015, 145, 960-968. [CrossRef]

25. He, K.; Hu, F.B.; Colditz, G.A.; Manson, J.E.; Willett, W.C.; Liu, S. Changes in Intake of fruits and vegetables in relation to risk of obesity and weight gain among middle-aged women. Int. J. Obes. Relat. Metab. Disord. 2004, 28, 1569-1574. [CrossRef]

26. Kahn, H.S.; Tatham, L.M.; Rodriguez, C.; Calle, E.E.; Thun, M.J.; Heath, C.W., Jr. Stable behaviors associated with adults' 10-year change in body mass index and likelihood of gain at the waist. Am. J. Public Health 1997, 87, 747-754. [CrossRef]

27. Ledoux, T.A.; Hingle, M.D.; Baranowski, T. Relationship of fruit and vegetable intake with adiposity: A systematic review. Obes. Rev. 2011, 12, e143-e150. [CrossRef]

28. Koplan, J.P.; Liverman, C.T.; Kraak, V.I.; Wisham, S.L. Progress in Preventing Childhood Obesity: How do We Measure Up; The National Academic Press: Washington, DC, USA, 2007; pp. 1-476. [CrossRef]

29. Van Ansem, W.J.; Schrijvers, C.T.; Rodenburg, G.; van de Mheen, D. Is there an association between the home food environment, the local food shopping environment and children's fruit and vegetable intake? Results from the Dutch INPACT Study. Public Health Nutr. 2012, 7, 1206-1214. [CrossRef]

30. Shier, V.; Nicosia, N.; Datar, A. Neighborhood and home food environment and children's diet and obesity: Evidence from military personnel's installation assignment. Soc. Sci. Med. 2016, 158, 122. [CrossRef]

31. Arcan, C.; Neumark-Sztainer, D.; Hannan, P.; Van Den Berg, P.; Story, M.; Larson, N. Parental eating behaviours, home food environment and adolescent intakes of fruits, vegetables and dairy foods: Longitudinal findings from project EAT. Public Health Nutr. 2007, 10, 1257-1265. [CrossRef]

32. Lora, K.R.; Branscum, P.W.; Chen, S.; Wakefield, D. Home food environment factors associated with hispanic preschoolers' intake of fruits and vegetables. Fam. Community Health 2019, 42, 261-270. [CrossRef]

33. Groele, B.; Głąbska, D.; Gutkowska, K.; Guzek, D. Mother's fruit preferences and consumption support similar attitudes and behaviors in their children. Int. J. Environ. Res. Public Health 2018, 15, 2833. [CrossRef]

34. Groele, B.; Głąbska, D.; Gutkowska, K.; Guzek, D. Mothers' vegetable consumption behaviors and preferences as factors limiting the possibility of increasing vegetable consumption in children in a national sample of polish and Romanian respondents. Nutrients 2019, 11, 1078. [CrossRef]

35. Sharman, S.J.; Skouteris, H.; Powell, M.B.; Watson, B. Factors related to the accuracy of self-reported dietary intake of children aged 6 to 12 years elicited with interviews: A systematic review. J. Acad. Nutr. Diet. 2016, 116, 76-114. [CrossRef]

36. Mathieu, N.P.; Sommer, E.C.; Mitchell, S.J.; Barkin, S.L. Urban latino families' food built environment and young children's produce consumption. J. Health Care Poor Underserved 2016, 27, 1899-1908. [CrossRef] 